\title{
A Novel Ceramic Membrane Reactor System For the Continuous Enzymatic Synthesis of Oligosaccharides
}

\author{
M. Ebrahimi ${ }^{a}$, L. Placido ${ }^{a}$, L. Engel ${ }^{a}$, K. Shams Ashaghi ${ }^{a}$, P. Czermak ${ }^{\text {a,b }}$ \\ Institute of Biopharmaceutical Technology -IBPT-, University of Applied Sciences Giessen- \\ Friedberg, Wiesenstrasse 14, 35390 Giessen, Germany ${ }^{\mathrm{a}}$. \\ Kansas State University, Dept. of Chemical Engineering, Manhattan KS, USA ${ }^{\mathrm{b}}$ \\ Corresponding Authors: peter.czermak@tg.fh-giessen.de \\ mehrdad.ebrahimi@tg.fh-giessen.de
}

Keywords: Ceramic Membrane, Oligosaccharides, Lactose Hydrolysis, Enzyme Membrane Reactor, $\beta-$ Galactosidase, Cross-Flow Filtration, Ultrafiltration

This paper published as: Ebrahimi M, L. Placido, L. Engel, K. Shams Ashaghi, P. Czermak: A Novel Ceramic Membrane Reactor System for the Continuous Enzymatic Synthesis of Oligosaccharides, Desalination 250 (3) (2010) p. 1105-1108.

\begin{abstract}
The continuous enzymatic production of galactosyl-oligosaccharides (GOS) from lactose as a substrate using a new type of ceramic membrane reactor system was investigated. GOS are non-digestible oligosaccharides and have recently attracted interest as prebiotics. However, the composition of oligosaccharides fraction and the variability in $\beta$-glycosidic linkages depends on the enzyme source. In the study presented below, native, physically immobilized, ß-galactosidase from Klyveromyces lactis (EC 3.2.1.23) was used as enzyme to catalyse transgalactosylation reaction to produce GOS, competed against the hydrolysis of lactose into its two component monosaccharides, glucose and galactose. To optimize GOS yielded, process conditions were varied: The average residence time of the enzyme was varied in the range of 13 to $24 \mathrm{~min}$, the trans-membrane pressure (TMP) was in the range of 1 to 2 bar and the initial concentration of substrate was varied from 10 to $30 \%(\mathrm{w} / \mathrm{w})$. Regarding the conditions investigated here, the maximum oligosaccharide concentration exceeded $38 \%$ $(\mathrm{w} / \mathrm{w})$ when the average residence time was $24 \mathrm{~min}$, the TMP was 2 bar and an initial lactose concentration of $30 \%(\mathrm{w} / \mathrm{w})$ was adjusted.
\end{abstract}

\section{Introduction}

During enzymatic hydrolysis of lactose into its two component monosaccharides, glucose and galactose, using $\beta$-galactosidase (EC 3.2.1.23), the enzyme is also able to transfer galactose to the hydroxyl groups of galactose or glucose in a process called "transgalactosylation" and, thus, produces galacto-oligosaccharides (GOS). GOS consist of galactosyl-galactose chain terminated trough glucose and are the desired by-products of the enzymatic catalysis $[1,2]$. The composition of the GOS fraction varies in chain length and in the interconnection of the monomer units with varying B-glycosidic linkages depending on the enzyme source (Fig.1). Opposed to the hydrolysation of lactose, GOS are very slowly hydrolyzed both in vivo and in vitro. GOS produced here are low-molecular, not viscose, water-soluble liquid dietary fibers [3], which are stable at elevated temperatures and at low $\mathrm{pH}$. GOS are considered as physiologically active functional food and enhance the growth of Bifido bacteria in the intestine [4].

Recently, various chemical and enzymatic methods for the production of GOS from disaccharide substrates have been developed. The chemical synthesis of GOS requires multiple protection and de-protection steps of specific molecular groups, possessing a complexity causing chemically driven synthesis little attractive for industrial applications. To 
overcome this challenge, new strategies for the continuous production of GOS in innovative enzymatic membrane bioreactors have been previously developed [2-8]. Hence, enzymatic synthesis of oligosaccharides and their derivatives have been shown as promising alternatives to chemical synthesis. However, enzymatic synthesis of GOS and concurrent hydrolysis of lactose depend on several process parameters such as the initial concentration and nature of substrate (i.e., lactose), enzyme source, membrane properties (e.g., pore size and design) and the average residence time of the enzyme. Consequently, assessing continuous GOS production while varying the process parameters mentioned was addressed in the study presented below.

The application of a novel two-stage integrated ceramic membrane reactor system to physically immobilize ß-galactosidase from Klyveromyces lactis for the continuous production of galactosyl-oligosaccharides through enzymatic conversion of lactose as a substrate was investigated.

\section{Materials and Methods}

\section{Chemicals}

Deionised water, $5 \mathrm{mmol} / \mathrm{l}$ potassium phosphate containing $5 \mathrm{mmol} / 1 \mathrm{MgSO}_{4}(\mathrm{pH} 7.0)$ as a buffer in all experiments and food-grade lactose monohydrate $(99.95 \%$ pure, Meggle $\mathrm{GmbH}$, Wasserburg, Germany) were used. Other chemicals, entirely of p.a. quality, were purchased from VWR International GmbH (Darmstadt, Germany).

\section{Membranes}

Tubular ceramic membranes (Table 1) were used for ultrafiltration (atech innovations $\mathrm{GmbH}$, Gladbeck, Germany). Membranes used have an asymmetric structure consisting of one support layer $\left(\mathrm{Al}_{2} \mathrm{O}_{3}\right)$ with large pores and a low-pressure decay and one separation layer $\left(\mathrm{TiO}_{2}\right)$ to control the permeation flux. Membrane (1) has an outer diameter of $10 \mathrm{~mm}$ and a total active filtration area of $13.5^{*} 10^{-3} \mathrm{~m}^{2}$. Membrane (2) exhibits an inner diameter of $16 \mathrm{~mm}$ and a total active filtration area of $20.1 * 10^{-3} \mathrm{~m}^{2}$.

\section{Enzyme}

The commercially available enzyme used was ß-galactosidases, Maxilact® L 2000 (GistBrocades NV, Delft, Holland), which was highly purified, liquid and prepared from Klyveromyces lactis and hold an activity of $2000 \mathrm{NLU} / \mathrm{g}$; whereas one NLU is defined as the quantity of enzyme that liberates $1 \mu \mathrm{mol}$ of o-nitrophenol from o-nitrophenyl-ß-Dgalactopyranoside (ONPG) per minute under standard conditions. The enzyme had a molecular weight exceeding 135,000 Dalton [9]. Further properties specific to the enzyme are given (Table 2). Different concentrations of enzyme-buffer solution $(2.5$ and $5 \%(\mathrm{w} / \mathrm{w}))$ were prepared adding different amounts of the enzyme to potassium phosphate buffer.

\section{Continuous Ceramic Membrane Reactor System}

Continuous production of oligosaccharides from lactose was performed using the laboratory equipment shown schematically (Fig. 2). A continuous stirred tank reactor (CSTR) was used together with a membrane module in a stainless steel housing. The ceramic membrane reactor is tubular and contains two coaxial, cylindrical monoliths with a mono flow channel for the substrate (Membrane (1)). The enzymes were confined in the annular space (volume about $43.5 \mathrm{ml}$ ) defined by two separating walls (Membranes $(1,2)$ ). Oligosaccharides were synthesized at $40^{\circ} \mathrm{C}$ in $5 \mathrm{mmol} / 1$ potassium phosphate buffer containing $5 \mathrm{mmol} / 1 \mathrm{MgSO}_{4}$ using various initial lactose concentrations ranging from 10 to $30 \%(\mathrm{w} / \mathrm{w})$. The TMP was about 1 to 2 bar with shaking. During processing the lactose solution was pumped into the inner compartment of the membrane reactor (substrate flow channel) using a peristaltic pump (Fig. 2). The substrate permeated in radial direction across the inner membrane (1) to the annular 
space where enzymatic hydrolysis occurred. Products (glucose, galactose, and oligosaccharides) contained in the permeate and the unconverted lactose passed through the outer membrane (2) due to the TMP. Assessing the driving force of the membrane separation, the TMP was determined measuring the inlet $\left(\mathrm{P}_{1}\right)$ and outlet $\left(\mathrm{P}_{2}\right)$ fluid pressures and averaging these values. The permeate was collected in the outer compartment. No permeate was recycled.

\section{Membrane cleaning}

Fouling of the membrane surface during processing decreases the productivity of the membrane and is responsible for limitation on performance of the enzyme membrane reactor system used. Membranes fouled through substrate, enzyme and products were cleaned with pure water and lye solutions $(1 \%(\mathrm{w} / \mathrm{w}) \mathrm{NaOH}-S o l u t i o n$, Ultrasil P3-14, Ultrasil P3-10 for 30 to $60 \mathrm{~min}$ ). Cleaning efficiency after membrane cleaning was evaluated determining the water flux recovery after cleaning relative to initial water flux.

\section{Determination of carbohydrates}

Carbohydrates containing glucose, galactose, oligosaccharides and the amounts of unconverted lactose were analyzed in the permeate utilizing high performance thin-layer chromatography (HPTLC) using a Camag system (Linomat 5, TLC Scanner 3, Camag GmbH, Berlin, Germany). A representative HPTLC chromatogram of products obtained from the production process described is shown (Fig. 3).

\section{Determination of the enzyme activity}

The initial and final enzyme activity was measured for each experiment incubating the enzyme and the substrate, o-Nitrophenyl- $\beta$-D-galactopyranosid (o-NPG), at $30^{\circ} \mathrm{C}$ for $5 \mathrm{~min}$. The absorbance was detected at $420 \mathrm{~nm}$.

\section{Protein determination}

Protein was determined utilizing a dye binding method (Bradford) and bovine serum albumin (BSA) as standard protein [10].

\section{Results}

\section{Oligosaccharide concentrations at different average residence times}

The amount and type of the oligosaccharides formed is determined by several parameters including enzyme source, concentration and nature of the substrate, degree of conversion of the substrate and reaction conditions [1]. Paradigmatically, data obtained through the continuous production of oligosaccharides as a function of the average residence time where ß-galactosidase was physically immobilized using a two-stage integrated ceramic membrane reactor are shown (experimental conditions were: initial lactose concentration, 30\%; volume of enzyme/buffer solution, $100 \mathrm{ml}$; enzyme concentration, 2.5\% (w/w); $\mathrm{pH} 6.7$; temperature, $40^{\circ} \mathrm{C}$ ) (Fig. $4 \mathrm{a}$ and Fig. 4b). Using an average residence time of $16 \mathrm{~min}$, the maximum oligosaccharide concentration exceeded $38 \%$ (w/w) (Fig. 4a). Besides, the permeate flux of membrane (2) decreased from initially 23 to $11 \mathrm{l} /\left(\mathrm{h}^{*} \mathrm{~m}^{2}\right)$ after $180 \mathrm{~min}$ run time at 2 bar TMP. Testing the enzyme activity in permeate, no enzyme leakage through the membrane was detected.

\section{Oligosaccharide concentrations at different lactose concentrations}

A main parameter affecting the yields of transgalactolysation products, substrate concentration increased shifts the equilibrium of the two reactions described towards the transgalactolysation $[11,12]$. Thus, the initial lactose concentration was varied from $10 \%$ to $30 \%(\mathrm{w} / \mathrm{w})$ and reactions were detected for $120 \mathrm{~min}$ (Fig. 5). Samples were taken at regular time intervals for further carbohydrate analytics. Data indicate increasing production of 
oligosaccharides from $13 \%$ to $31 \%(\mathrm{w} / \mathrm{w})$ after $1 \mathrm{~h}$ process time and using a higher initial lactose concentration as indicated (Fig. 5). This is evidence for lactose intensified competing with $\mathrm{H}_{2} \mathrm{O}$ as an acceptor for galatosyl residues when the initial lactose concentration was increased.

\section{Conclusions}

Aiming at a new type of ceramic membrane reactor system for the continuous enzymatic synthesis of oligosaccharides from lactose using physically immobilized $\beta$-galactosidase from Kluyveromyces lactis, data obtained show that physically immobilized enzyme used in a twostage integrated ceramic membrane reactor may perform well in the continuous production of GOS from lactose as substrate. Significant oligosaccharide concentrations were achieved in permeate, at different average residence times (Fig. 4a, 4b) and initial lactose concentrations (Fig. 5). A maximum oligosaccharide concentration yielded exceeded $38 \%(\mathrm{w} / \mathrm{w})$ when an average residence time of $24 \mathrm{~min}$, a TMP of 2 bar and an initial lactose concentration of $30 \%$ $(\mathrm{w} / \mathrm{w})$ were adjusted.

However, process optimization of the newly developed ceramic membrane reactor system in continuous mode including further investigation of process parameters used is needed. To maximize oligosaccharide yield in the permeate, the effect of process parameters (initial substrate concentration, various TMP, the use of different enzymes and different residence times) and statistical combinations of these parameters affecting the oligosaccharide yield have to be investigated.

Though, advantages of the novel type of ceramic membrane reactor presented include the possibility of continuous production of GOS, simple enzyme separation and recovery through physical immobilization, efficient optimization of average residence time of enzyme and reduced hydrolysis of newly formed GOS through rapid separation of the product from the enzyme. Thus, the process presented has proven its use aiming at oligosaccharide production and is promising when GOS production exceeding a laboratory scale is requested.

\section{Acknowledgements}

Atech innovations $\mathrm{GmbH}$, Gladbeck, Germany and Meggle $\mathrm{GmbH}$, Germany are gratefully acknowledged for the donation of ceramic membranes and lactose, respectively.

\section{References}

[1] Mahoney R. R. Food Chemistry 63 (1998) 147-154

[2] Czermak P., Ebrahimi M., Grau K., Netz S., Sawatzki G., Pfromm P.H. Journal of Membrane Science 232 (2004) 85-91

[3] Solange I. Mussatto, Ismael M. Mancilha. A review. Carbohydrate Polymers 68 (2007) 587-597

[4] R. Tanaka, H. Takayama, M. Morotomi, T. Kuroshima, S. Ueyama, K. Matsumoto, A. Kuroda, and M. Mutai, Bifidobact. Microflora. 2 (1983) 17-24.

[5] L. Engel, M. Ebrahimi, P. Czermak. Desalination 224 (2008) 46-51

[6] Ebrahimi M., L. Engel, S. Peter, K. Grau, P. Czermak. Desalination 200 (2006)509510

[7] Gonzalez R, M. Ebrahimi, P. Czermak. The Open Food Science Journal submitted for publication 5 (2008)

[8] L. Engel, P. Schneider, M. Ebrahimi, P. Czermak. The Open Food Science Journal 1 (2007) 17-22 
[9] Gekas V., López-Leiva M. A literature review Process Biochemistry, February (1985) $2-12$

[10] Bradford, M. M. Analytical Biochemistry, 72 (1976), 248-255.

[11] S. K. Khare, K. Jha, A.P. Gandhi. Food Chemistry 51 (1994) 29-31

[12] T. Maugard, D. Gaunt, M. D. Legoy, T. Besson. Biotechnology Letters 25 (2003) 623-629

Table1: Ceramic membrane material and properties.

\begin{tabular}{ccccc}
\hline \hline Membrane & MWCO & Material & $\mathrm{pH}$ range & Max. Temp. \\
\hline $\mathrm{UF}_{-} \mathrm{TiO}_{2}$ & $10,000 \mathrm{Da} / 20,000 \mathrm{Da}$ & $\mathrm{AL}_{2} \mathrm{O}_{3} / \mathrm{TiO}_{2}$ & $0-14$ & $121^{\circ} \mathrm{C}$ \\
\hline \hline
\end{tabular}

Table 2: Source and properties of enzyme

\begin{tabular}{ccccc}
\hline \hline Trade name & Derived from & Opt. $\mathrm{pH}$ & Opt. Temp. & Activity [U/g] \\
\hline Maxilact L 2000 & Kluyveromyces lactis & $6.8-7.0$ & $35-40{ }^{\circ} \mathrm{C}$ & 2000 \\
\hline \hline
\end{tabular}

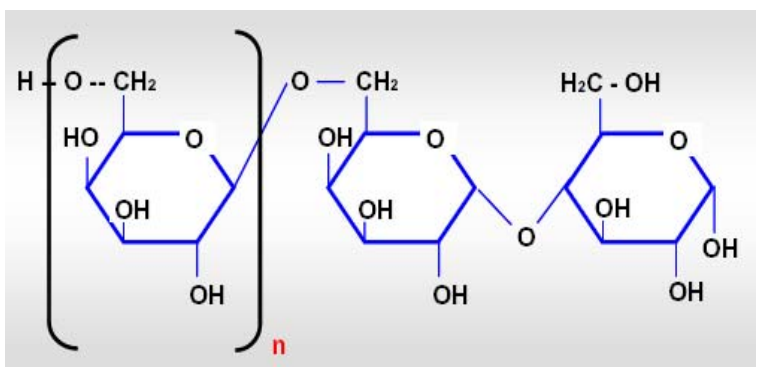

Fig. 1. General chemical structure of GOS

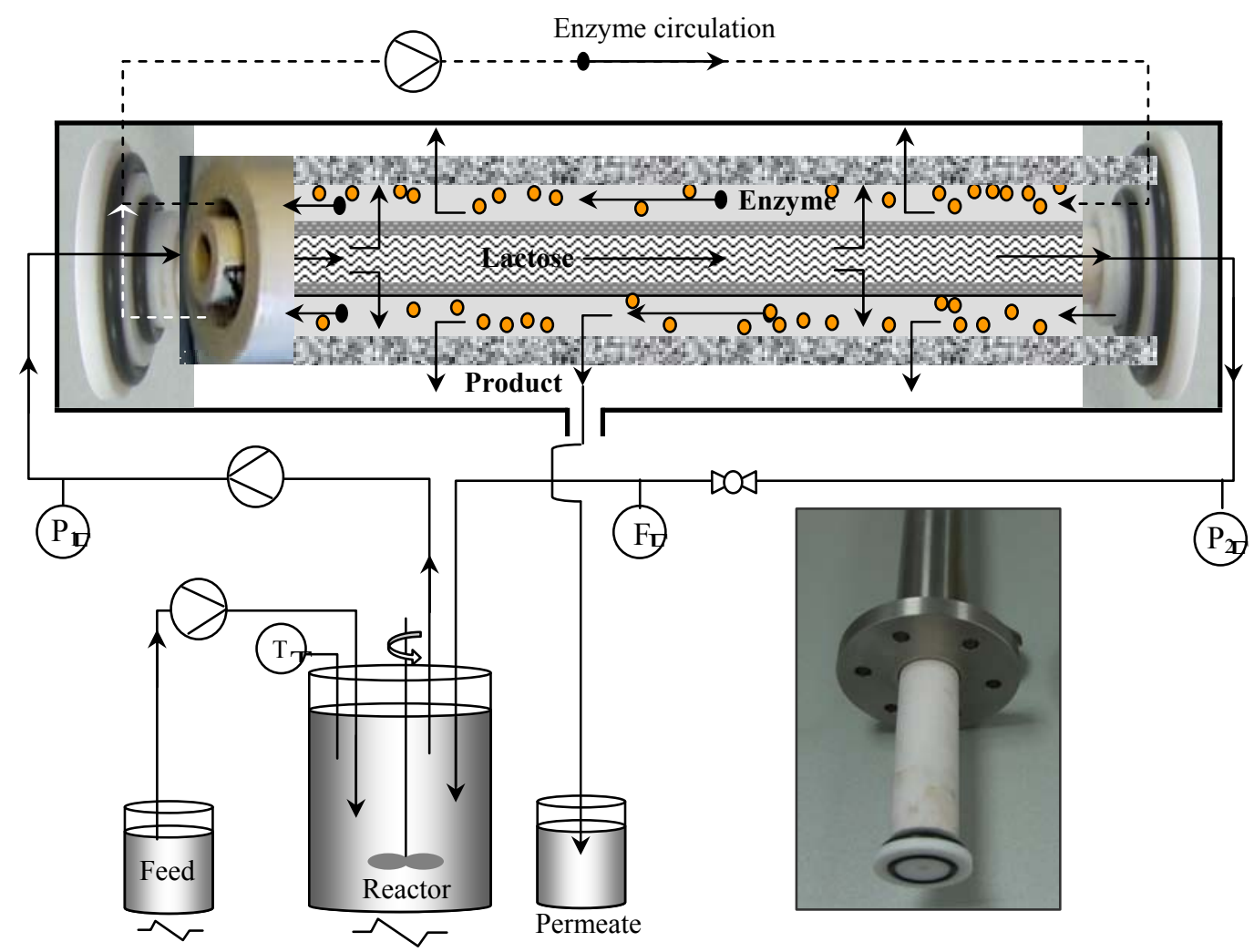

Membrane 1; Membrane 2; 图 Substrate flow; 四 Enzyme flow 
Fig. 2: Schematic diagram of continuous laboratory scale reactor/membrane system with physically immobilized $\beta$-galactosidase and enzyme circulation.

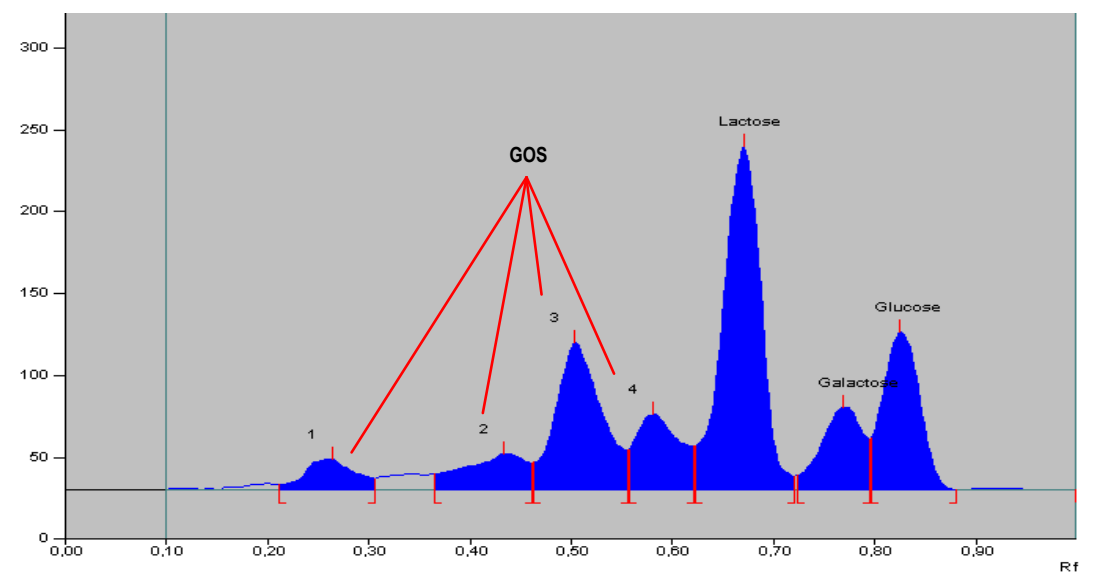

Fig. 3. HPTLC chromatogram of products obtained during continuous enzymatic synthesis of GOS (Sum of peaks 1-4) from lactose using enzyme Maxilact L 2000

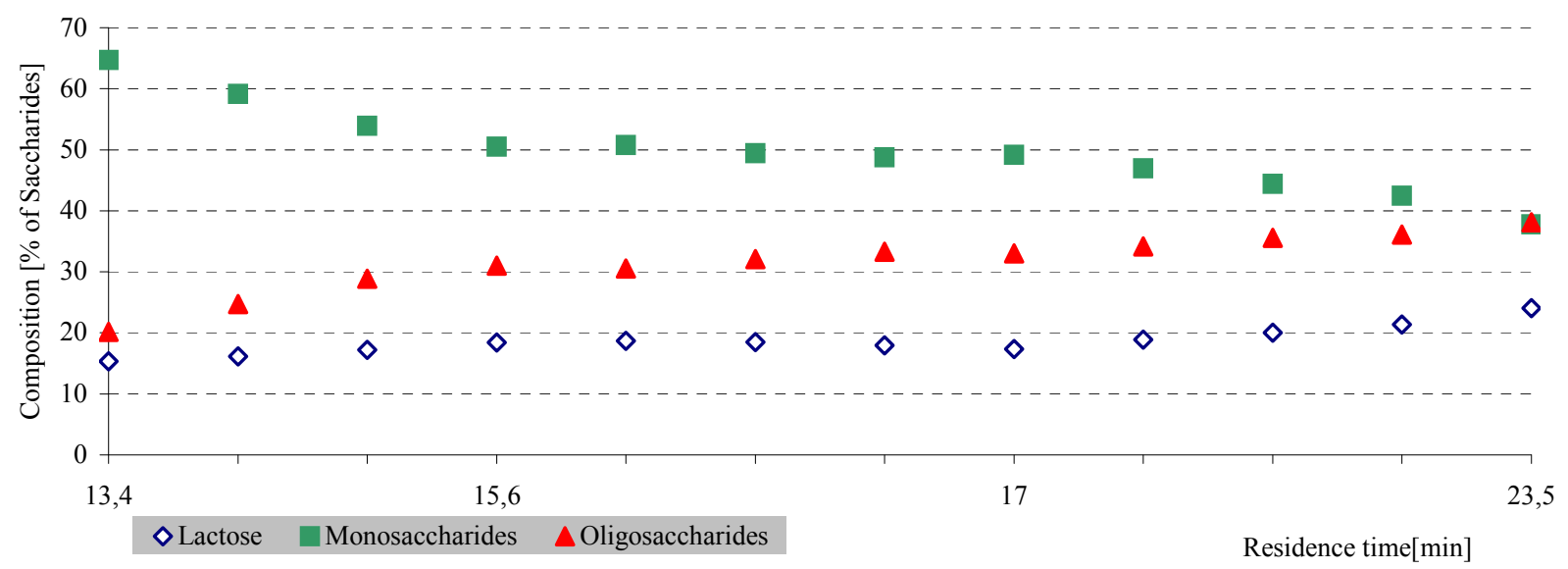

Fig. 4a) Continuous production of oligosaccharides from lactose in a two-stage integrated ceramic membrane reactor system as a function of the average residence time; process time, $180 \mathrm{~min}$; initial lactose concentration, $30 \%$; TMP, 2 bar; $40^{\circ} \mathrm{C} ; \mathrm{pH}, 6.7 ; 20,000$ Dalton ceramic membranes were used.

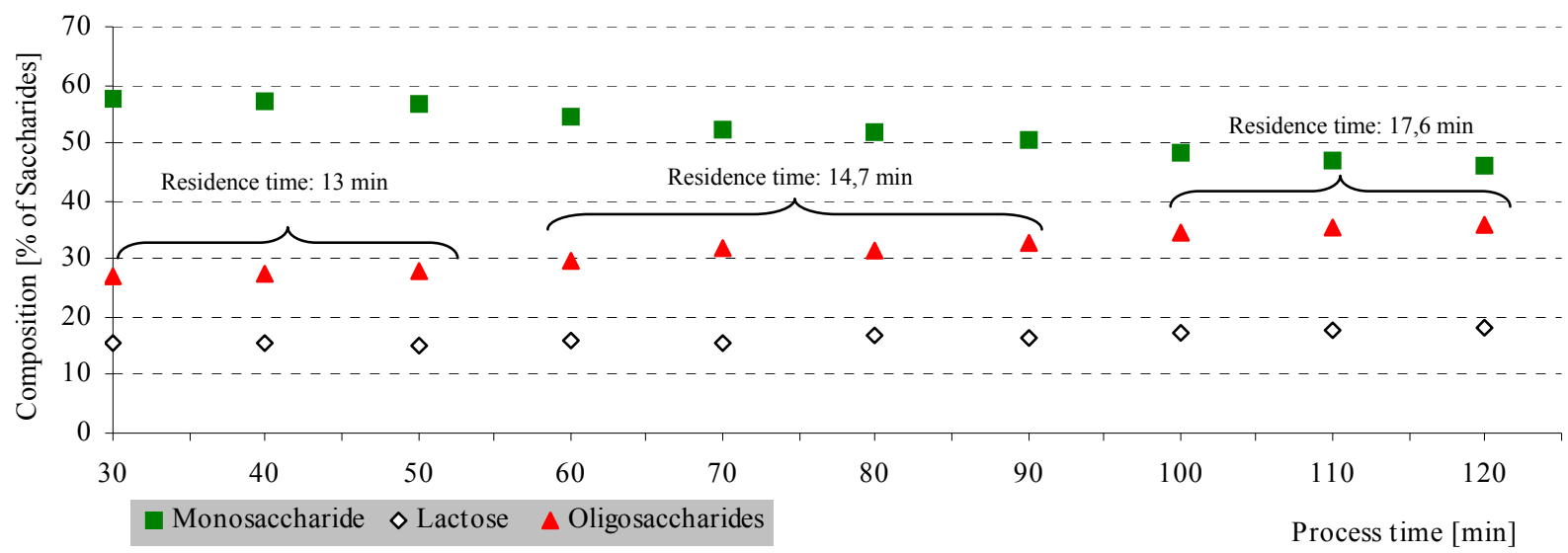


Fig. 4b) Continuous production of oligosaccharides from lactose in a two-stage integrated ceramic membrane reactor system as a function of the average residence time; process time, $120 \mathrm{~min}$; initial lactose concentration, 30\%; TMP, $1,7-1,8$ bar; $40^{\circ} \mathrm{C} ; \mathrm{pH}, 6.7 ; 20,000$ Dalton ceramic membranes were used.

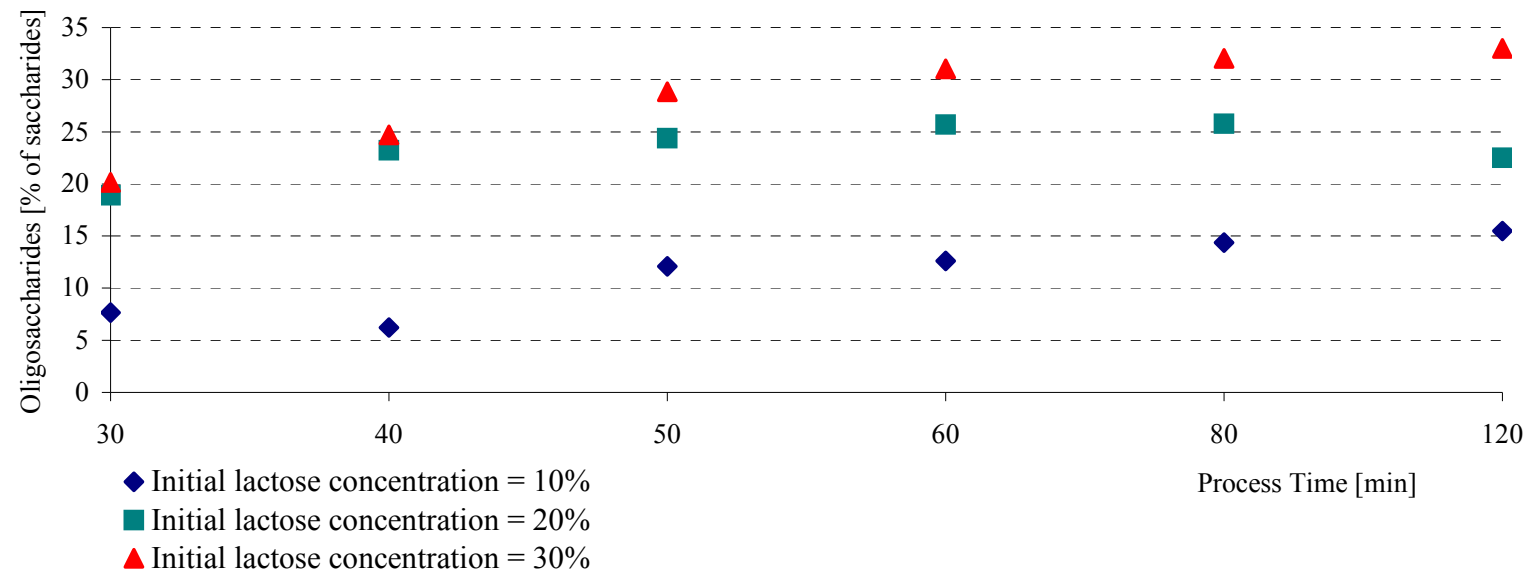

Fig. 5. Oligosaccharide concentration in permeate in a continuous mode membrane reactor system versus process time at different initial lactose concentrations 10, 20 and 30\%; TMP, 1,8 bar; $40^{\circ} \mathrm{C}$; $\mathrm{pH} 6.7 ; 20,000$ Dalton ceramic membranes were used. 